\title{
Supplier Selection Application Based on a Fuzzy Multiple Criteria Decision Making Methodology
}

\author{
Bulanık Çok Kriterli Karar Verme Metodolojisine Dayalı Tedarikçi Seçimi \\ Uygulaması
}

\author{
Dr. Hüseyin Selçuk KILIÇ \\ Marmara University, Engineering Faculty, Department of Industrial Engineering \\ huseyin.kilic@marmara.edu.tr
}

\begin{abstract}
Due to the increasing competitiveness in every sector of business life, being effective in every process of the organizations has been required. At this point, one of the most important processes is supplier selection process within the concept of supply chain management. If a systematic supplier selection methodology is performed, it will be possible to select the most suitable supplier and provide efficiency with respect to time, quality and cost. With this study, depending on the vague structure of the real working environment, an extensively used multi criteria decision making methodology TOPSIS is used within fuzzy environment. The proposed technique is applied in a real case and the most suitable suppliers are determined and ranked.
\end{abstract}

Keywords: Supply chain management, Supplier selection, Fuzzy TOPSIS.

\section{ÖZET}

İş hayatının her sektöründe rekabetin artmasından dolayı, organizasyonların bütün süreçlerinde verimli olunması gereksinimi doğmaktadır. Bu noktada, tedarik zinciri yönetimi kapsamında en önemli süreçlerden biri de tedarikçi seçme sürecidir. Sistematik bir tedarikçi seçme metodolojisi oluşturulması durumunda en uygun tedarikçinin seçilmesi, zaman, kalite ve maliyet açısından verimliliğin sağlanmasını mümkün kılacaktır. Bu çalışmayla, gerçek çalışma ortamının belirsiz yapısına bağh olarak, yaygın olarak kullanılan çok kriterli karar verme metodolojisi olan TOPSIS bulanık ortam altında kullanılmıştır. Önerilen teknik gerçek bir durum için kullanılmış ve en uygun tedarikçiler belirlenmiş ve sıralanmıştır.

Anahtar kelimeler: Tedarik zinciri yönetimi, Tedarikçi seçimi, Bulanık TOPSIS. 


\section{INTRODUCTION}

Supplier selection can be regarded as one of the most important activities of purchasing management in a supply chain (Amid, 2006). Supply chain management can be defined as a process including planning, implementing and controlling the supply chain network operations in the most efficient way (Bhattacharya, 2010). In other words, it includes all the events related with the flow and transformation of goods and services from the source point to the usage point (Büyüközkan, 2011).

Including so many uncontrollable and unpredictable factors affecting the decisions, supplier selection process is occasionally considered as a highly complex period (Bevilacqua et al., 2006). Different from the traditional cost based approaches, the supplier selection process is not accomplished by considering only cost factor. That's why it is regarded as a multiple criteria decision making problem.

Two kinds of supplier selection problem are seen in the literature. In the first one, the needs of a supplier can be satisfied by one supplier. Whereas, in the second one, the requirements can be satisfied partially by the supplier. That is, no supplier can satisfy the needs singly (Demirtas and Ustun, 2008). These two problem types are also called "single sourcing" and "multiple sourcing" (Ghodsypour and O'Brien, 1998).

Depending on its importance both in the academic world and real world applications, there have been a lot of studies using different criteria and different methodologies since Dickson (1966). In his study which can be regarded as one of the first studies about supplier selection problem, Dickson (1966) made a survey among purchasing managers and accomplished an analysis about the importance of 23 criteria. Among the criteria, the first three important ones were quality, delivery and performance history.

After Dickson (1966), a comprehensive literature review study was made by Weber et al. (1991). They analyzed 74 studies from 1967 to 1990. The ranking of the most popular criteria were net price, delivery and quality. The methods used in the study were mainly grouped into three categories such as linear weighting methods, mathematical programming models and statistical/probabilistic approaches. Following Weber (1991), other important literature review studies were accomplished by Degraeve et al. (2000), De Boer et al. (2001) and Ho et al. (2010).

The methods used in the supplier selection problems have been classified a little bit differently but mostly the same in the literature, one of the last classifications was made by Sanayei et al. (2010). According to the classification, there are six classes. These are multi 
attribute decision making techniques (MADM) (AHP, ANP, MAUT, outranking method, TOPSIS), multi-objective decision making and mathematical programming (LP, GP, MIP, DEA) statistical/probabilistic approaches, intelligent approaches (neural networks, casebased reasoning, expert system), hybrid approaches (AHP-LP, ANP-MIP, ANP-TOPSIS, Fuzzy-QFD) and others.

Considering multi-criteria structure of the supplier selection problem and the vagueness in real environment, fuzzy TOPSIS was thought to be a suitable technique for selecting the most suitable supplier. The proposed methodology was applied in a filter company for choosing the best supplier of one of its raw materials.

The rest of the paper is organized as follows. Part 2 includes literature review. TOPSIS and Fuzzy TOPSIS are explained in part 3. An application was provided in part 4 and conclusion was presented in part 5 with the reference following.

\section{LITERATURE REVIEW}

As mentioned in the previous part, there are comprehensive literature review studies performed before such as Weber (1991), Degraeve et al. (2000), De Boer et al. (2001) and Ho et al. (2010). The studies in the literature reviews were classified mainly with respect to selection criteria and methodologies used.

Regarding the last literature review accomplished by Ho et al. (2010), the most popular supplier selection criteria were obtained as quality, delivery and price, different from some rankings in the previous studies such as the ranking of Weber et al. (1991) in which the ranking was as price, delivery and quality. On the other hand, the methodologies stated in the study of Ho et al. (2010) were divided into two main groups such as individual approaches and integrated approaches. Within individual approaches; data envelopment analysis, mathematical programming , AHP, case-based reasoning, ANP, fuzzy set theory, simple multi-attribute rating technique and genetic algorithm were taken into account and within integrated approaches; integrated AHP approaches, integrated fuzzy approaches and the last sub-group under integrated approaches is other approaches. As can be concluded from the study of Ho et al. (2010), individual approaches were used more than integrated approaches. The most widely used three individual approaches were DEA, mathematical programming and AHP. Within the integrated approaches, the most popular one was integrated AHP approaches and specifically AHP-GP approach.

Since the literature about the supplier selection problem is huge, only a few of the recent studies in the last three years are taken into account. The related studies are as follows: 
In 2010, Bhattacharya (2010) improved an integrated approach for supplier selection problem. The approach consisted of analytic hierarchy process (AHP), quality function deployment (QFD) and cost factor measure (CFM). The proposed methodology was tested with datasets that were already in literature. Chamodrakas (2010) proposed a two stage model consisting of satisficing technique and fuzzy preference programming. The proposed approach was applied in a hypothetical metal manufacturing company. Lam et al. (2010) developed an approach based on Fuzzy Principal Component Analysis (FPCA) for material supplier selection problem. Within the approach, first of all, subjective evaluations of the decision makers were quantified by the triangular fuzzy numbers, second, selection criteria data was compressed via PCA and the multi-collinearity was removed among them and finally the suppliers were ranked with respect to linear combined scores. Sanayei et al. (2010) used fuzzy VIKOR for supplier selection problem. The proposed methodology was applied in a numerical example.

In 2011, Bilsel (2011) proposed a multi-objective stochastic sequential supplier allocation model for the supplier selection problem under uncertainty. Büyüközkan (2011) developed an approach based on analytic network process under fuzzy environment within multi-person decision-making schema. The proposed approach was applied in a real case including a number of suppliers. Dalalah et al. (2011) proposed a hybrid fuzzy multi-criteria decision making model including modified fuzzy DEMATEL and fuzzy TOPSIS for the supplier selection problem. For validating the proposed approach, a case study was conducted in a nutridar factory. Feng et al. (2011) developed a multi-objective model for supplier selection in multi-service outsourcing. Due to the NP-hard structure of the problem, they developed an algorithm based on tabu search for solving it. Güneri et al. (2011) developed an approach based on Adaptive Neuro-Fuzzy Inference System (ANFIS) for supplier selection problem. The proposed method was applied in a textile firm and the results obtained from ANFIS approach were compared with multiple regression method. Kara (2011) developed a combined methodology including a two-stage stochastic programming model and fuzzy TOPSIS to analyze the potential of suppliers and to choose the best of them in an uncertain multi-sourcing problem environment. A case study was conducted to show the validity of the proposed approach.

In 2012, Büyüközkan (2012) proposed an integrated method including DEMATEL, ANP and TOPSIS in fuzzy environment for green supplier evaluation. The hybrid methodology was used in a real case study. Che (2012) developed two optimization mathematical models for supplier clustering and selection. For solving the first model, integrated k-means and simulated annealing algorithm with the Taguchi method were proposed and for solving the second model, simulated annealing algorithm was used with the weights obtained from AHP method. The proposed approach was used in a case study. Chen et al. (2012) used AHP for constructing the structure of criteria and then for the 
decision matrices, they used consistent fuzzy preference relations (CFPR). They made an application in an electronic company regarding 15 criteria. Ferreira et al. (2012) proposed a method based on both influence diagram and fuzzy logic taking into account the learning and adaptation. A case study was conducted in the biodiesel supply chain.

\section{THEORETICAL BACKGROUND OF THE METHODOLOGY}

Although fuzzy TOPSIS is used in this study, theoretical information about both TOPSIS and Fuzzy TOPSIS are provided.

\subsection{TOPSIS}

TOPSIS which was firstly proposed by Hwang and Yoon (1981) is one of the mostly used multi-criteria decision making techniques. Within the technique, best alternative is determined regarding the nearness to the positive ideal solution and distance from the negative ideal solution. The steps of the methodology are as follows (Torlak et al., 2011):

Step 1: Decision matrix is normalized and $\mathrm{r}_{\mathrm{ij}}$ representing the normalized criteria rating is obtained.

$r_{i j}=\frac{\frac{1}{x_{i j}}}{\sqrt{\sum_{i=1}^{m} \frac{1}{x_{i j}^{2}}}}, i=1,2,3, \ldots, m ; j=1,2,3, \ldots, n$ for minimization objective

$r_{i j}=\frac{x_{i j}}{\sqrt{\sum_{i=1}^{m} x_{i j}^{2}}}, i=1,2,3, \ldots, m ; j=1,2,3, \ldots, n$ for maximization objective

Step 2: Weighted normalized decision matrix is formed as:

$v_{i j}=r_{i j} * w_{j}, i=1,2,3, \ldots, m ; j=1,2,3, \ldots, n$

Step 3: Positive ideal solution (PIS) and negative ideal solution (NIS) are obtained as:

$A^{*}=\left\{v_{1}^{*}, \ldots, v_{n}^{*}\right\}$ maximum values

$A^{-}=\left\{v_{1}^{-}, \ldots, v_{n}^{-}\right\}$minimum values

Step 4: Each alternative's distance from positive ideal solution and negative ideal solution are determined. 


$$
\begin{aligned}
& d_{i}^{*}=\sqrt{\sum_{j=1}^{n}\left(v_{i j}-v_{j}^{*}\right)^{2}}, i=1, \ldots, m \\
& d_{i}^{-}=\sqrt{\sum_{j=1}^{n}\left(v_{i j}-v_{j}^{-}\right)^{2}}, i=1, \ldots, m
\end{aligned}
$$

Step 5: The relative closeness of each alternative to the ideal solution is calculated.

$$
C C_{i}=\frac{d_{i}^{-}}{d_{i}^{*}+d_{i}^{-}}, i=1, \ldots, m
$$

Step 6: The alternatives are ranked according to the values of $\mathrm{CC}_{\mathrm{i}}$ and the biggest one is chosen.

\subsection{FUZZY TOPSIS}

TOPSIS is widely used in various kinds of problems. But there are arguments about it regarding the inadequacy of it while handling the vagueness about the decision maker's preferences. For overcoming this drawback, fuzzy TOPSIS and the extensions of it were proposed (Dağdeviren, 2009).

The steps of fuzzy TOPSIS can be expressed in some slightly different ways but mainly in a similar way in the literature (Torlak et al., 2011; Çevikcan et al., 2009 and Çelik et al., 2009). Within presented steps, it is benefited from the study of Çevikcan et al., (2009).

Step 1: In the first step, the importance of criteria and the ratings of alternatives with respect to the criteria are evaluated. The decision makers $\left(D_{1}, D_{2}, \ldots, D_{k}\right)$ evaluate each criterion $\left(C_{1}, C_{2}, \ldots, C_{n}\right)$ by using linguistic variables as shown in Table 1 and rate the alternatives according to Table 2 .

Table 1: Linguistic variables for the evaluation of criteria (Çevikcan et al., 2009).

\begin{tabular}{ll}
\hline Linguistic variable & Fuzzy number \\
\hline Very Low (VL) & $(0,0,0.1)$ \\
Low $(\mathrm{L})$ & $(0,0.1,0.3)$ \\
Medium Low (ML) & $(0.1,0.3,0.5)$ \\
Medium (M) & $(0.3,0.5,0.7)$ \\
Medium High (MH) & $(0.5,0.7,0.9)$ \\
High $(\mathrm{H})$ & $(0.7,0.9,1)$ \\
Very High $(\mathrm{VH})$ & $(0.9,1,1)$ \\
\hline
\end{tabular}

Table 2: Linguistic variables for the ratings (Çevikcan et al., 2009). 


\begin{tabular}{ll}
\hline Linguistic variable & Fuzzy number \\
\hline Very Poor (VP) & $(0,0,1)$ \\
Poor (P) & $(0,1,3)$ \\
Medium Poor (MP) & $(1,3,5)$ \\
Fair (F) & $(3,5,7)$ \\
Medium Good (MG) & $(5,7,9)$ \\
Good (G) & $(7,9,10)$ \\
Very Good (VG) & $(9,10,10)$ \\
\hline
\end{tabular}

Step 2: Linguistic terms are transformed into triangular fuzzy numbers by benefiting from the Table 1 . Rating of alternatives $\left(\tilde{x}_{i j}\right)$ and the importance of the criteria $\left(\tilde{w}_{j}\right)$ are obtained by using the equations (9) and (10) below.

$$
\begin{aligned}
& \tilde{x}_{i j}=\frac{1}{K}\left(\tilde{x}_{i j}^{1}+\tilde{x}_{i j}^{2}+\ldots+\tilde{x}_{i j}^{K}\right), \tilde{x}_{i j}=\left(a_{i j}, b_{i j}, c_{i j}\right) \\
& \tilde{w}_{j}=\frac{1}{K}\left(\widetilde{w}_{j}^{1}+\tilde{w}_{j}^{2}+\ldots+\widetilde{w}_{j}^{K}\right), \quad \tilde{w}_{j}=\left(w_{j 1}, w_{j 2}, w_{j 3}\right)
\end{aligned}
$$

Step 3: Normalization is performed by using the linear scale transformation. The related equations are shown below:

If criterion is benefit then $c_{j}^{*}=\max _{i} C_{i j}$ and equation (11) is used.

$$
\widetilde{R}=\left[\tilde{r}_{i j}\right]_{m \times n} \Rightarrow \tilde{r}_{i j}=\left(\frac{a_{i j}}{c_{j}^{*}}, \frac{b_{i j}}{c_{j}^{*}}, \frac{c_{i j}}{c_{j}^{*}}\right)
$$

Otherwise, if criterion is cost, $a_{j}^{-}=\min _{i} a_{i j}$ and the following equation (12) is used.

$$
\tilde{r}_{i j}=\left(\frac{a_{j}^{-}}{c_{i j}}, \frac{a_{j}^{-}}{b_{i j}}, \frac{a_{j}^{-}}{a_{i j}}\right)
$$

Step 4: Firstly, aggregated weight matrix is obtained then the weighted normalized fuzzy decision matrix is found with the help of equation (13).

$$
\begin{aligned}
& \tilde{V}=\left[\tilde{v}_{i j}\right]_{m \times n} \quad i=1,2, \cdots, m \quad j=1,2, \cdots, n \\
& \tilde{v}_{i j}=\tilde{r}_{i j} \cdot \tilde{w}_{j}
\end{aligned}
$$

Step 5: The distance of each alternative from fuzzy positive and fuzzy negative ideal solutions are obtained as follows:

$$
A^{*}=\left(v_{1}^{*}, v_{2}^{*}, \ldots, v_{n}^{*}\right) \quad \text { where } v_{j}^{*}=(1,1,1) A^{-}=\left(v_{1}^{-}, v_{2}^{-}, \ldots ., v_{n}^{-}\right) \quad \text { where } v_{j}^{-}=(0,0,0)
$$


$d_{i}^{*}=\sum_{j=1}^{n} d\left(\tilde{v}_{i j}, \tilde{v}_{j}^{*}\right) \quad i=1,2, \cdots, m \quad d_{i}^{-}=\sum_{j=1}^{n} d\left(\tilde{v}_{i j}, \tilde{v}_{j}^{-}\right) \quad i=1,2, \cdots, m$

Step 6: The fuzzy closeness coefficient $C C_{i}$ is determined and the highest of them is chosen as the best alternative.

$$
C C_{i}=\frac{d_{i}^{-}}{d_{i}^{*}+d_{i}^{-}} \quad i=1,2, \cdots, m
$$

\section{APPLICATION IN A FILTER COMPANY}

An application is performed in a new company which has been in the filter sector for approximately 2 years. Mainly, the products used in the ventilation are produced by the company. Such products are panel filters, roll filters, bag filters, compact filters, carbon filters etc. Since it is a new company, it wants to choose the right suppliers and increase its efficiency so as to be competitive in the sector. For this aim, galvanized metal sheet which is one of the main raw materials is taken into consideration.

So as to determine the criteria and alternatives for the supplier selection process, a meeting was performed with two managers in the company. Quality, cost, delivery time and institutionalization were chosen as the selection criteria and three firms named as A, B and C are chosen as the alternatives.

The steps of the fuzzy TOPSIS are performed as follows:

Step 1: Evaluation of the criteria and alternative ratings with respect to the criteria assessed by the decision makers are shown in the Tables 3 and 4 .

Table 3: The evaluation of decision makers for the importance weight of the criteria

\begin{tabular}{lcc}
\hline Criteria & D1 & D2 \\
\hline C1 (Quality) & $\mathrm{H}$ & $\mathrm{VH}$ \\
C2 (Cost) & $\mathrm{VH}$ & $\mathrm{H}$ \\
C3 (Delivery Time) & $\mathrm{H}$ & $\mathrm{M}$ \\
C4 (Institutionalization) & $\mathrm{MH}$ & $\mathrm{MH}$ \\
\hline
\end{tabular}

Table 4: The evaluation of decision makers for alternative ratings

\begin{tabular}{ccccccccc}
\hline & & C1 & & & C2 & & C3 & \multicolumn{2}{c}{ C4 } \\
\hline & D1 & D2 & D1 & D2 & D1 & D2 & D1 & D2 \\
\hline A1 & MG & MG & G & G & G & G & MP & MG \\
A2 & G & MG & MG & MG & MG & MG & MP & F \\
A3 & MG & F & MG & MG & MG & F & P & F \\
\hline
\end{tabular}


Step 2: Linguistic terms are transformed into triangular fuzzy numbers and both fuzzy decision matrix and fuzzy weights of criteria are shown as in Table 5.

Table 5: Fuzzy decision matrix and fuzzy weights of criteria

\begin{tabular}{ccccc}
\hline & C1 & C2 & C3 & C4 \\
\hline A1 & $(5,7,9)$ & $(7,9,10)$ & $(7,9,10)$ & $(3,5,7)$ \\
A2 & $(6,8,9.5)$ & $(5,7,9)$ & $(5,7,9)$ & $(2,4,6)$ \\
A3 & $(4,6,8)$ & $(5,7,9)$ & $(4,6,8)$ & $(1.5,3,5)$ \\
Weight & $(0.8,0.95,1)$ & $(0.8,0.95,1)$ & $(0.5,0.7,0.85)$ & $(0.5,0.7,0.9)$ \\
\hline
\end{tabular}

Step 3: Normalization is performed as in Table 6.

Table 6: Fuzzy normalized decision matrix

\begin{tabular}{lllll}
\hline & \multicolumn{1}{c}{ C1 } & \multicolumn{1}{c}{ C2 } & \multicolumn{1}{c}{ C3 } & \multicolumn{1}{c}{ C4 } \\
\hline A1 & $(0.53,0.74,0.95)$ & $(0.7,0.9,1)$ & $(0.7,0.9,1)$ & $(0.43,0.71,1)$ \\
A2 & $(0.63,0.84,1)$ & $(0.5,0.7,0.9)$ & $(0.5,0.7,0.9)$ & $(0.29,0.57,0.86)$ \\
A3 & $(0.42,0.63,0.84)$ & $(0.5,0.7,0.9)$ & $(0.4,0.6,0.8)$ & $(0.21,0.43,0.71)$ \\
\hline
\end{tabular}

Step 4: The weighted normalized fuzzy decision matrix is obtained by using the equation (13) as shown in the Table 7.

Table 7: Fuzzy weighted normalized decision matrix

\begin{tabular}{lllll}
\hline & \multicolumn{1}{c}{ C1 } & \multicolumn{1}{c}{ C2 } & \multicolumn{1}{c}{ C3 } & \multicolumn{1}{c}{ C4 } \\
\hline A1 & $(0.42,0.70,0.95)$ & $(0.56,0.86,1)$ & $(0.35,0.63,0.85)$ & $(0.22,0.5,0.9)$ \\
A2 & $(0.50,0.80,1)$ & $(0.4,0.67,0.9)$ & $(0.25,0.49,0.77)$ & $(0.15,0.4,0.78)$ \\
A3 & $(0.34,0.6,0.84)$ & $(0.4,0.67,0.9)$ & $(0.2,0.42,0.68)$ & $(0.11,0.3,0.64)$ \\
\hline
\end{tabular}

Step 5: The distances from fuzzy positive and negative ideal solutions are calculated and shown in Table 8. 
Step 6: The fuzzy closeness coefficient $C C_{i}$ for all the alternatives is calculated and shown in Table 8. Regarding the coefficient values, the best supplier is A1.

Table 8: The distances from positive and negative ideal solutions

\begin{tabular}{lccc}
\hline & $\mathbf{A}^{*}$ & $\mathbf{A}^{-}$ & $\mathbf{C C}_{\mathbf{i}}$ \\
\hline A1 & 2.814 & 4.850 & 0.633 \\
A2 & 3.236 & 4.388 & 0.576 \\
A3 & 3.717 & 3.811 & 0.506 \\
\hline
\end{tabular}

\section{CONCLUSION}

Supplier selection process is one of the most important activities in the supply chain management. For providing a sustainable system, a good supplier selection methodology should be applied. Different from the classical methods which only consider the cost, new methods regard a lot of criteria such as quality, delivery time etc. For incorporating vagueness to the methodology and conforming to the multi-criteria structure of the supplier selection problem, an extensively used multi-criteria decision making methodology, fuzzy TOPSIS, is proposed in this study. A case study in a filter company is provided for showing the applicability of the methodology. Four criteria; quality, cost, delivery time and institutionalization are taken into account and the best supplier among three alternative suppliers is chosen by applying the steps of fuzzy TOPSIS. Different multi-criteria decision making models can be applied for the same problem and results can be compared in the further studies. Moreover, hybrid methodologies incorporating the strong sides of the different methodologies can be performed.

\section{BIBLIOGRAPHY}

Amid, A., Ghodsypour, S. H., \& O'Brien, C. (2006). Fuzzy multiobjective linear model for supplier selection in a supply chain. International Journal of Production Economics, 104, 394-407.

Bevilacqua, M., Ciarapica, F. E., \& Giacchetta, G. (2006). A fuzzy-QFD approach to supplier selection. Journal of Purchasing \& Supply Management, 12, 14-27.

Bhattacharya, A., Geraghty, J., \& Young, P. (2010). Supplier selection paradigm: An integrated hierarchical QFD methodology under multiple-criteria environment. Applied Soft Computing, 10, 1013-1027. 
Bilsel, R. U., \& Ravindran, A. (2011). A multi-objective chance constrained programming model for supplier selection under uncertainty. Transportation Research Part B, 45, 1284-1300.

Büyüközkan, G., \& Çiftçi, G. (2011). A novel fuzzy multi-criteria decision framework for sustainable supplier selection with incomplete information. Computers in Industry, 62, 164-174.

Büyüközkan, G., \& Çiftçi, G. (2012). A novel hybrid MCDM approach based on fuzzy DEMATEL, fuzzy ANP and fuzzy TOPSIS to evaluate green suppliers. Expert Systems with Applications, 39, 3000-3011.

Chamodrakas, I., Batis, D., \& Martakos, D. (2010). Supplier selection in electronic marketplaces using satisficing and fuzzy AHP. Expert Systems with Applications, 37, 490-498.

Che, Z. H. (2012). Clustering and selecting suppliers based on simulated annealing algorithms. Computers and Mathematics with Applications, 63, 228-238.

Chen, Y., \& Chao, R. (2012). Supplier selection using consistent fuzzy preference relations. Expert Systems with Applications, 39, 3233-3240.

Çelik, M., Çebi, S., Kahraman, C., \& Er İ. D. (2009). Application of axiomatic design and TOPSIS methodologies under fuzzy environment for proposing competitive strategies on Turkish container ports in maritime transportation network. Expert Systems with Applications, 36, 4541-4557.

Çevikcan, E., Çebi, S., \& Kaya, İ. (2009). Fuzzy VIKOR and fuzzy axiomatic design versus to fuzzy TOPSIS: An application of candidate assessment. Journal of Multi-Valued Logic and Soft Computing, 15, 181-208.

Dağdeviren, M., Yavuz, S., \& Kılınç, N. (2009). Weapon selection using the AHP and TOPSIS methods under fuzzy environment. Expert Systems with Applications, 36, 8143-8151.

Dalalah, D., Hayajneh, M., \& Batieha, F. (2011). A fuzzy multi-criteria decision making model for supplier selection. Expert Systems with Applications, 38, 8384-8391.

De Boer, L., Labro, E., \& Morlacchi, P. (2001). A review of methods supporting supplier selection. European Journal of Purchasing \& Supply Management, 7, 75-89.

Degraeve, Z., Labro, E., \& Roodhooft, F. (2000). An evaluation of supplier selection methods from a total cost of ownership perspective. European Journal of Operational Research, 125(1), 34-59. 
Demirtas, E. A., \& Üstün, Ö. (2008). An integrated multi-objective decision making process for supplier selection and order allocation. Omega, 36, 76-90.

Dickson, G. (1966). An analysis of vendor selection systems and decisions. Journal of Purchasing, 2(1), 5-17.

Feng, B., Fan, Z., \& Li, Y. (2011). A decision method for supplier selection in multi-service outsourcing, International Journal of Production Economics, 132, 240-250.

Ferreira, L., \& Borenstein, D. (2012). A fuzzy-Bayesian model for supplier selection. Expert Systems with Applications, Article in Press.

Ghodsypour, S. H., \& O’Brien C. (1998). A decision support system for supplier selection using an integrated analytic hierarchy process and linear programming. International Journal of Production Economics, 56-57, 199-212.

Güneri, A. F., Ertay, T., \& Yücel, A. (2011). An approach based on ANFIS input selection and modeling for supplier selection problem. Expert Systems with Applications, 38, 1490714917.

Ho, W., Xu, X. D., \& Prasanta K. (2010). Multi-criteria decision making approaches for supplier evaluation and selection: A literature review. European Journal of Operational Research, 202, 16-24.

Hwang, C. L., \& Yoon, K. (1981). Multiple attributes decision making methods $\mathcal{E}$ applications. New York: Springer.

Kara, S. S. (2011). Supplier selection with an integrated methodology in unknown environment. Expert Systems with Applications, 38, 2133-2139.

Lam, K., Tao, R., \& Lam, M. C. (2010). A material supplier selection model for property developers using fuzzy principal component analysis. Automation in Construction, 19, 608-618.

Sanayei, A., Mousavi, S. F., \& Yazdankhah, A. (2010). Group decision making process for supplier selection with VIKOR under fuzzy environment. Expert Systems with Applications, 37, 24-30.

Torlak, G. Sevkli, M. Sanal, M., \& Zaim, S. (2011). Analyzing business competition by using fuzzy TOPSIS method: an example of Turkish domestic airline industry. Expert Systems with Applications, 38(4), 3396-3406.

Weber, C. A., Current, J. R., \& Benton, W. C. (1991). Vender selection criteria and methods. European Journal of Operational Research, 50, 2-18. 